\title{
REVISION THEORY
}

\section{Time to take stock.}

\section{BY BLAIZE M. KAYE}

$\mathrm{T}$ hemba reread what he'd written. "I must know if this will work. It's 11:35 p.m., 12 Sept. 2015. I'm in the garage. In 2 minutes, I'm going to open the third drawer down on the left side of my workbench."

That was it.

There were two possibilities.

One: the drawer would remain as empty as it had been since the day he'd bought the bench. That wouldn't necessarily mean that the device didn't work, but it would be disappointing.

Two: the drawer would no longer be empty.

He folded the note carefully and focused on what he intended to do with it. He would place it in a white envelope, address it to himself, and deposit it in the red and blue postbox next to the notice board at the supermarket.

He waited.

11:37:59 p.m.

Themba opened the drawer. Inside lay a yellowed envelope.

He trembled as he retrieved the letter and opened it. There, written in a faded blue script he didn't recognize, was a simple response:

"Yes, it works."

Themba sat, stunned for a moment. Then, a wave of relief passed over him. Graduate school, the disastrous postdoc, the humiliation of taking a job in industry while his peers were getting their own labs. None of that meant anything now. Not next to this.

"It works," he said. And then, correcting himself: "It's going to work."

He glanced at the drawer and turned his attention back to the letter. He'd seen it before, just after they'd delivered the workbench. He remembered opening the drawer a hundred times since and seeing the letter just lying there. Why hadn't he read it, he wondered, or just thrown it away?

This was to be expected when reweaving history, he thought. Every moment from the intervention to the present is affected and the whole course of the future as well. These weren't false memories, he'd really seen the letter in the drawer before and yet, in another sense, he couldn't have.

He picked up his own note and added:

"PS I've been struggling with counterfactual dampening, don't tell me how to do it, but am I on the right track? Is it even a problem?"

The letter in the drawer had always read:

"I don't know anything about 'counterfactual dampening' but, yes, your machine works."

Had the letter changed? He remembered adding the PS just a moment ago, but he was

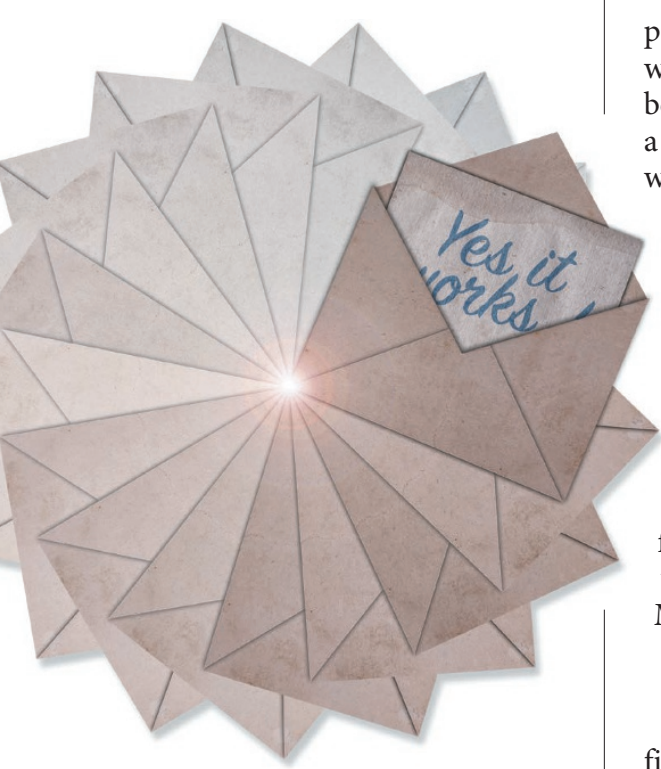

certain that the response had always mentioned the dampening issue. And who could be using the machine without even recognizing one of the most fundamental terms in temporal and possible world mechanics?

He added to his note:

"PPS Who is this?"

And the response from the drawer had always read:

"Dear Dad, this is Pat. I don't know anything about 'counterfactual dampening', but, yes, your machine works."

Pat. Patricia? His little girl, whom he'd bathed and changed just hours earlier. Whom he'd kissed goodnight before sneaking out to his workshop.

Thema again added to his note.

"PPPS Pat. Do I know you're writing to me?"

And Patricia's response had always read:

"Dad, you don't know that I'm doing this, but I wanted to tell you that, yes, it works. I $\rightarrow$ NATURE.COM

Follow Futures: @NatureFutures

f go.nature.com/mtoodm don't know anything about 'counterfactual dampening', sorry. I love you and miss you. Patricia."
Themba stared at the note for a long while. Something about the tone bothered him.

He crossed out the line he'd just added and wrote:

"PPPS Why don't I know that you're writing this to me?"

And Patricia's response had always read:

"Dear Dad, I miss you so much. I suppose you must have been on the right track with the 'counterfactual dampening' issue because, yes, your machine works. I've spent a long time trying to decide how, and even whether, I should answer the last question in your note. We missed you so much during those early years, but Mom said your work was important, that it could change everything. Once you'd shown that you could move things through time, we thought we'd have you back. But it just got worse. You said there were still problems with the device, and we saw less of you then. Mom and I left. Miriam found you. It was a heart attack. Your note was among your papers. I haven't told Mom about it. It would make her too sad.

I love you.

Patricia."

He'd been crying from the moment he'd first opened and read Patricia's letter. There was no relief or joy in this success, not if it cost him his family and, ultimately, his life.

He disconnected the device and placed it in the open drawer. He was done with it.

Then he picked up the letter he'd written, the letter that would eventually end up in Patricia's hands, and tore it to pieces while focusing on his intention never to mail it.

He wanted to hold his daughter and his wife.

He wanted to meddle with time no longer.

He threw the scraps of paper into the small red wastebasket next to the bench.

He reached for Patricia's response but it was no longer there - it had never been there - and Themba was left with his hand suspended in mid-air with the strongest feeling that he was about to do something important but had no idea what it was.

He supposed it had something to do with his work and so he opened the drawer, retrieved the device, and began running diagnostics. There was still much to do.

Blaize M. Kaye lives in Kwazulu-Natal, South Africa, with his wife and child. He spends his time thinking about books, brains and computers. 